\title{
Does Postoperative Glenoid Retroversion Affect the 2-Year Clinical and Radiographic Outcomes for Total Shoulder Arthroplasty?
}

\author{
Benjamin C. Service MD, Jason E. Hsu MD, Jeremy S. Somerson MD, \\ Stacy M. Russ BA, Frederick A. Matsen III MD
}

Received: 4 March 2017 / Accepted: 23 June 2017/Published online: 5 July 2017

(C) The Association of Bone and Joint Surgeons (B) 2017

\begin{abstract}
Background While glenoid retroversion and posterior humeral head decentering are common preoperative features of severely arthritic glenohumeral joints, the relationship of postoperative glenoid component retroversion to the clinical results of total shoulder arthroplasty
\end{abstract}

One of the authors certifies that he (FAM) or a member of his immediate family, has or may receive payments or benefits, during the study period, an amount of less than USD 10,000, from Elsevier (Amsterdam, The Netherlands).

One of the authors certifies that he (JSS) or a member of his immediate family, has or may receive payments or benefits, during the study period, an amount of less than USD 10,000, from Springer Publishing Company (New York, NY, USA).

All ICMJE Conflict of Interest Forms for authors and Clinical Orthopaedics and Related Research ${ }^{\circledR}$ editors and board members are on file with the publication and can be viewed on request.

The University of Washington approved the human protocol for this investigation, and each author certifies that all investigations were conducted in conformity with ethical principles of research.

This work was done at the Department of Orthopaedics and Sports Medicine, University of Washington, Seattle, WA, USA.

Electronic supplementary material The online version of this article (doi:10.1007/s11999-017-5433-3) contains supplementary material, which is available to authorized users.

\section{B. C. Service}

Orthopaedic Surgery and Sports Medicine, Orlando Health, Orlando, FL, USA

J. E. Hsu, S. M. Russ, F. A. Matsen III

Department of Orthopaedics and Sports Medicine, University of

Washington, Seattle, WA, USA

J. S. Somerson

Department of Orthopaedic Surgery and Rehabilitation, The

University of Texas Medical Branch, Galveston, TX, USA
(TSA) is unclear. Studies have indicated concern for inferior outcomes when glenoid components are inserted in $15^{\circ}$ or more retroversion.

Questions/Purposes In a population of patients undergoing TSA in whom no specific efforts were made to change the version of the glenoid, we asked whether at 2 years after surgery patients having glenoid components implanted in $15^{\circ}$ or greater retroversion had (1) less improvement in the Simple Shoulder Test (SST) score and lower SST scores; (2) higher percentages of central peg lucency, higher Lazarus radiolucency grades, higher mean percentages of posterior decentering, and more frequent central peg perforation; or (3) a greater percentage having revision for glenoid component failure compared with patients with glenoid components implanted in less than $15^{\circ}$ retroversion.

Methods Between August 24, 2010 and October 22, 2013, information for 201 TSAs performed using a standard allpolyethylene pegged glenoid component were entered in a longitudinally maintained database. Of these, $171(85 \%)$ patients had SST scores preoperatively and between 18 and 36 months after surgery. Ninety-three of these patients had preoperative radiographs in the database and immediate postoperative radiographs and postoperative radiographs taken in a range of 18 to 30 months after surgery. Twenty-

\footnotetext{
F. A. Matsen III ( $\square)$

Department of Orthopaedics and Sports Medicine, University of Washington Medical Center, 1959 NE Pacific Street, Box 356500, Seattle, WA 98195-6500, USA

e-mail: matsen@uw.edu; matsen@u.washington.edu
} 
two patients had radiographs that were inadequate for measurement at the preoperative, immediate postoperative, or latest followup time so that they could not be included. These excluded patients did not have substantially different mean age, sex distribution, time of followup, distribution of diagnoses, American Society of Anesthesiologists class, alcohol use, smoking history, BMI, or history of prior surgery from those included in the analysis. Preoperative retroversion measurements were available for 11 (11 shoulders) of the 22 excluded patients. For these 11 shoulders, the mean $( \pm \mathrm{SD})$ retroversion was $15.8^{\circ} \pm 14.6^{\circ}$, five had less than $15^{\circ}$, and six had more than $15^{\circ}$ retroversion. We analyzed the remaining 71 TSAs, comparing the 21 in which the glenoid component was implanted in $15^{\circ}$ or greater retroversion (mean $\pm \mathrm{SD}, 20.7^{\circ} \pm 5.3^{\circ}$ ) with the 50 in which it was implanted in less than $15^{\circ}$ retroversion (mean $\pm \mathrm{SD}, 5.7^{\circ} \pm 6.9^{\circ}$ ). At the 2-year followup (mean \pm $\mathrm{SD}, 2.5 \pm 0.6$ years; range, 18-36 months), we determined the latest SST scores and preoperative to postoperative improvement in SST scores, the percentage of maximal possible improvement, glenoid component radiolucencies, posterior humeral head decentering, and percentages of shoulders having revision surgery. Radiographic measurements were performed by three orthopaedic surgeons who were not involved in the care of these patients. The primary study endpoint was the preoperative to postoperative improvement in the SST score.

Results With the numbers available, the mean ( \pm SD) improvement in the SST $(6.7 \pm 3.6$; from $2.6 \pm 2.6$ to 9.3 \pm 2.9 ) for the retroverted group was not inferior to that for the nonretroverted group $(5.8 \pm 3.6$; from $3.7 \pm 2.5$ to 9.4 $\pm 3.0)$. The mean difference in improvement between the two groups was $0.9(95 \% \mathrm{CI},-2.5$ to $0.7 ; \mathrm{p}=0.412)$. The percent of maximal possible improvement (\%MPI) for the retroverted glenoids $(70 \% \pm 31 \%)$ was not inferior to that for the nonretroverted glenoids $(67 \% \pm 44 \%)$. The mean difference between the two groups was $3 \%(95 \% \mathrm{CI}$, $-18 \%$ to $12 \%$; $\mathrm{p}=0.857$ ). The 2 -year SST scores for the retroverted $(9.3 \pm 2.9)$ and the nonretroverted glenoid groups $(9.4 \pm 3.0)$ were similar (mean difference, $0.2 ; 95 \%$ CI, -1.1 to $1.4 ; \mathrm{p}=0.697)$. No patient in either group reported symptoms of subluxation or dislocation. With the numbers available, the radiographic results for the retroverted glenoid group were similar to those for the nonretroverted group with respect to central peg lucency (four of 21 [19\%] versus six of 50 [12\%]; $p=0.436$; odds ratio, 1.7; 95\% CI, 0.4-6.9), average Lazarus radiolucency scores $(0.5$ versus 0.7 , Mann-Whitney $U$ p value $=0.873$; Wilcoxon rank sum test $\mathrm{W}=512$, $\mathrm{p}$ value $=0.836)$, and the mean percentage of posterior humeral head decentering $(3.4 \% \pm 5.5 \%$ versus $1.6 \% \pm 6.0 \% ; \mathrm{p}=0.223)$. With the numbers available, the percentage of patients with retroverted glenoids undergoing revision ( 0 of 21 [0\%]) was not inferior to the percentage of those with nonretroverted glenoids (three of 50; [6\%]; $\mathrm{p}=0.251$ ).

Conclusion In this small series of TSAs, postoperative glenoid retroversion was not associated with inferior clinical results at 2 years after surgery. This suggests that it may be possible to effectively manage arthritic glenohumeral joints without specific attempts to modify glenoid version. Larger, longer-term studies will be necessary to further explore the results of this approach.

Level of Evidence Level III, therapeutic study.

\section{Introduction}

In shoulders with severe glenohumeral arthritis, the preoperative pathologic features commonly include glenoid retroversion and posterior decentering of the humeral head relative to the glenoid face [9, 45, 46, 53, 54]. Surgical treatment of these pathologic features can be a challenge; in their presence glenoid failure attributable to "rocking horse" loosening is a concern $[17,23,28,50,55,56]$. Some authors suggest that glenoid components should be inserted in $15^{\circ}$ or less retroversion to avoid inferior outcomes [3, 6, 10, 17, 47]. Several methods to address increased glenoid retroversion have been described [5, 21, 46], including overreaming the anterior "high side" of the glenoid (Fig. 1) [14, 59], posterior glenoid bone grafting [16, 34, 43], posteriorly augmented glenoid components [40, 44, 49, 64], and reverse total shoulder arthroplasty (TSA) [33].

In our practice, we do not specifically attempt to address glenoid retroversion by overreaming the anterior glenoid, bone grafting, or use of special glenoid components. Instead, we strive to preserve glenoid bone stock by conservatively reaming the glenoid to a single concavity and managing any intraoperative posterior decentering of the humeral head with appropriate humeral head sizing, anteriorly eccentric humeral head components, and/or rotator interval plication [19].

From the available literature, it is unclear whether the clinical outcomes for standard glenoid components implanted in $15^{\circ}$ or more retroversion are inferior to those for standard glenoid components implanted in less than $15^{\circ}$ retroversion. Therefore, in a population of patients undergoing TSA with a standard glenoid component in whom no specific efforts were made to change the retroversion of the glenoid, we asked whether patients having glenoid components implanted in $15^{\circ}$ or more retroversion had (1) less improvement in the Simple Shoulder Test (SST) score and lower SST scores at 2 years; (2) higher percentages of central peg lucency, higher Lazarus radiolucency grades, higher mean percentage posterior decentering, and more frequent central peg perforation; or (3) a greater percentage having revision compared with patients with glenoid components implanted in less than $15^{\circ}$ retroversion. 

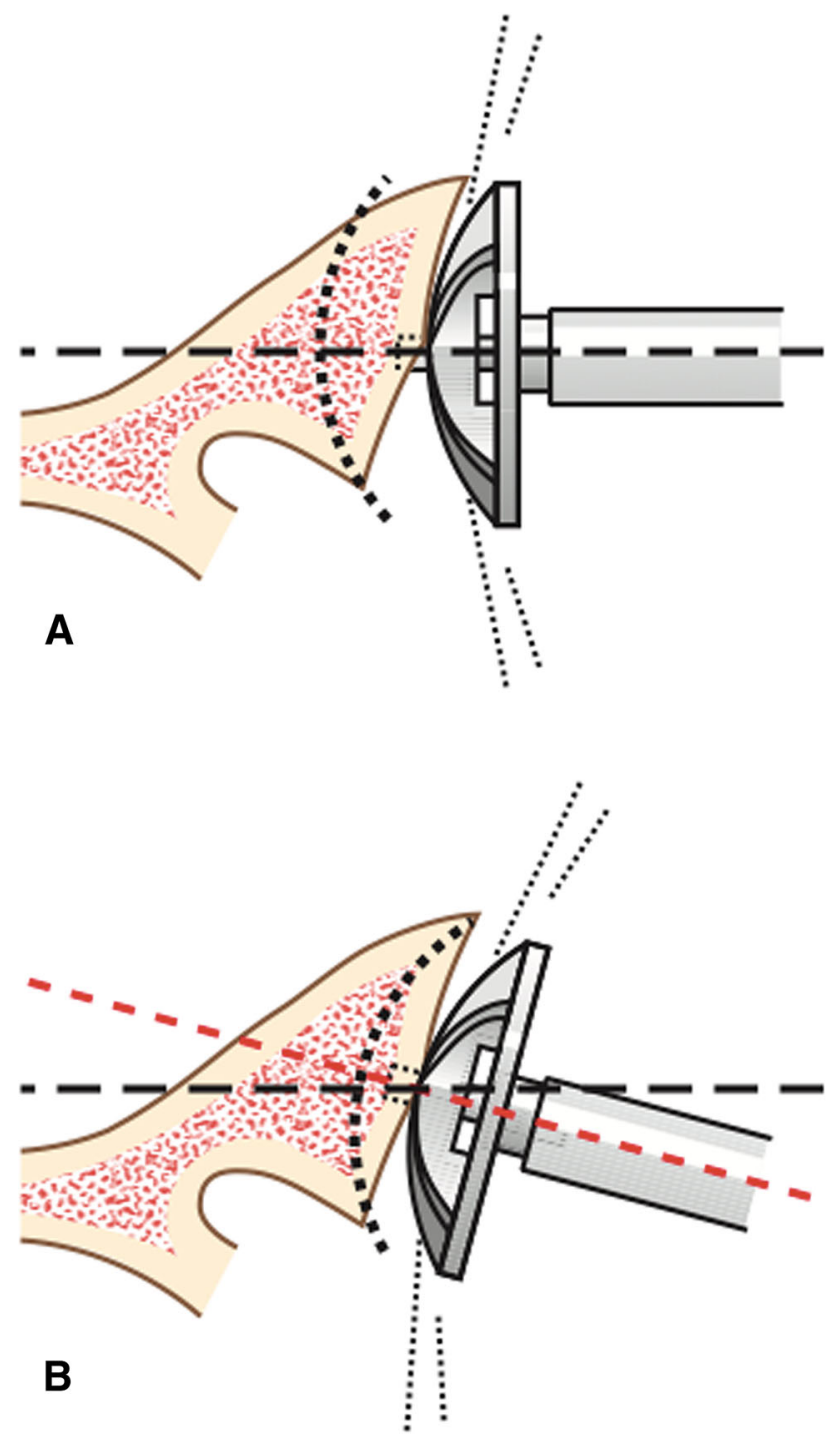

Fig. 1A-B (A) Correcting glenoid retroversion by reaming the anterior 'high side' may result in removal of a substantial amount of glenoid bone. (B) Reaming without attempting to correct glenoid retroversion preserves glenoid bone stock. (Published with permission from Elsevier from Matson FA 3rd, Lippitt SB, Rockwood CA Jr, Wirth MA. Glenohumeral arthritis and its management. Rockwood and Matsen's The Shoulder, 5th Edition. 2016:831-1042.)

\section{Methods}

The human research protocol for this study was approved by the University of Washington's institutional review board (IRB 38897).

\section{Study Design and Participants}

Between August 24, 2010 and October 22, 2013, we performed 201 TSAs with a standard all-polyethylene glenoid component with a fluted central peg with three peripheral pegs (Global ${ }^{\circledR}$ Advantage ${ }^{\circledR}$; Anchor Peg, DePuy Synthes, Warsaw, IN, USA). Of these, 171 (85\%) patients had SST scores preoperatively and between 18 and 36 months after surgery. Ninety-three of these patients had available preoperative radiographs and immediate postoperative and postoperative radiographs taken in a range of 18 to 30 months after surgery. In the judgment of authors (JEH, BCS, JSS) not involved in the care of these patients, 22 patients had inadequate radiographs for measurement at the preoperative or latest followup so they could not be included in the analysis. The remaining 71 patients were the subjects of this analysis; this represents $76 \%$ of the 93 patients for whom 2-year radiographs were available, $42 \%$ of the 171 patients with 2-year followup SST scores, and $35 \%$ of the TSAs performed during the period of this study. The mean $( \pm \mathrm{SD})$ followup was $2.5 \pm 0.6$ years (range, 18-36 months) for these 71 patients.

\section{Surgical Technique}

The shoulder was approached through an anterior deltopectoral incision. The joint was exposed using a subscapularis peel. After humeral head and osteophyte resection, a single glenoid concavity (Fig. 2) was created by conservative glenoid reaming without specifically attempting to correct version (Fig. 3). Reaming was limited to that necessary to conform the reamed bony glenoid surface to the back of the glenoid component. The goal of this approach is to preserve the maximal amount of glenoid bone [61]. The flutes of the central peg were filled with autograft. The three peripheral pegs were cemented after the holes were dried with a carbon dioxide spray (CarboJet ${ }^{\circledR}$; Kinamed Inc, Camarillo, CA, USA). If the peripheral holes penetrated the glenoid bone, the hole was filled with cement, but the cement was not pressurized. The humeral component was fixed with impaction autografting [27]. A humeral head component thickness was selected that allowed $150^{\circ}$ forward elevation and $60^{\circ}$ internal rotation with the arm in $90^{\circ}$ abduction [30]. If the head trial decentered posteriorly by more than $50 \%$ of the width of the glenoid when the arm was elevated in a forward direction, we replaced the standard trial head with an anteriorly eccentric humeral head (Fig. 4) [19, 26]. If adequate stability was not achieved with the use of an anteriorly eccentric humeral head component alone, plication of the rotator interval between the upper border of the subscapularis and the anterior border of the supraspinatus was performed (Fig. 5) [15, 32]. The subscapularis was repaired using six strands of Number 2 nonabsorbable suture. On the afternoon of surgery, patients were started on supine active assisted forward elevation exercises to $150^{\circ}$ and progressed to strengthening exercises 
Fig. 2A-D (A) The residual cartilage over the anterior glenoid is removed with a curette revealing the biconcavity of the glenoid bone surface. (B) The crest between the two concavities is removed with a pinecone burr. (C) The glenoid reamer is positioned so that the minimal amount of bone is removed. (D) The result is a single concavity with maximal bone preservation. (Published with permission from Elsevier from Matson FA 3rd, Lippitt SB, Rockwood CA Jr, Wirth MA. Glenohumeral arthritis and its management. Rockwood and Matsen's The Shoulder, 5th Edition. 2016:831-1042.)

at 6 weeks after surgery starting with the two-hand supine press.

\section{Study Variables}

Preoperative and postoperative functional status at latest followup was assessed using the SST, which was selected because of its excellent psychometric properties, brevity, low cost, international use, responsiveness, and high degree of correlation with lengthier and more-complex instruments (Table 1) [1, 2, 13, 35, 41, 51, 52, 62]. Hsu et al. [22] reported an extensive validation for the use of the SST in patients having shoulder arthroplasty. From the results of clinic visits and from routinely mailed followup questionnaires documented in a longitudinally maintained database, we recorded the preoperative SST, 2-year postoperative SST, preoperative to postoperative change in SST, percent of maximum possible improvement (\%MPI) in the SST calculated as: (followup SST score - preoperative score $) * 100 \%$ / (12 - preoperative score) $[11,31,48]$, and any history of postoperative dislocation or subluxation.

Standardized preoperative and postoperative radiographs included AP and axillary lateral views [17-19, 48]. Adequate observation of the spinoglenoid notch confirmed proper orientation of the axillary view $[19,29]$. Because of the demonstrated utility and reproducibility of this method and to avoid unnecessary cost and radiation exposure, preoperative and postoperative CT scans were not obtained [29]. Acceptability of the images and radiographic assessments of glenoid version, glenoid type, postoperative glenoid lucencies, and glenoid decentering were performed by two board-eligible and one fellowship trained shoulder surgeons who were not involved in the care of these patients (BCS, JSS, JEH), who were blinded to the clinical outcome, and who were experienced in making these measurements [19] (Fig. 6). Measurement of preoperative humeral head decentering also was done (Fig. 7). The immediate postoperative version of the glenoid component was measured as the angle between the scapular body plane and a line through the metal marker of the central peg (Fig. 8). Posterior humeral head decentering was measured
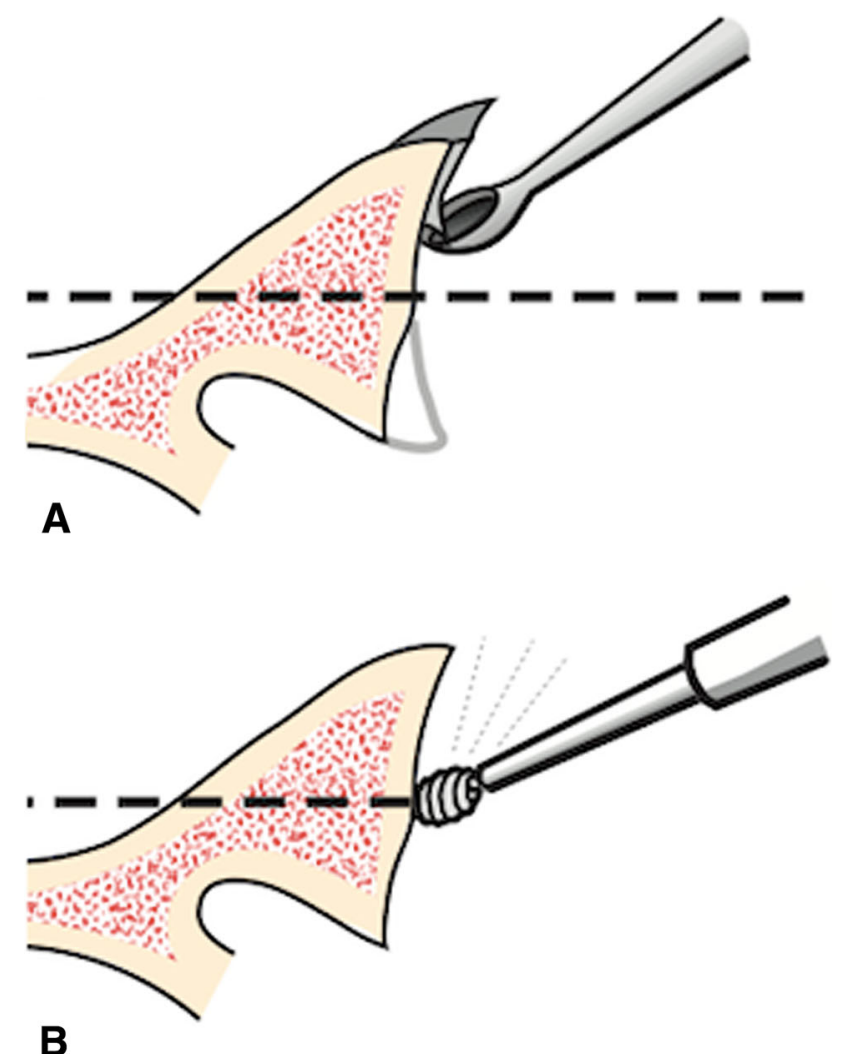

B
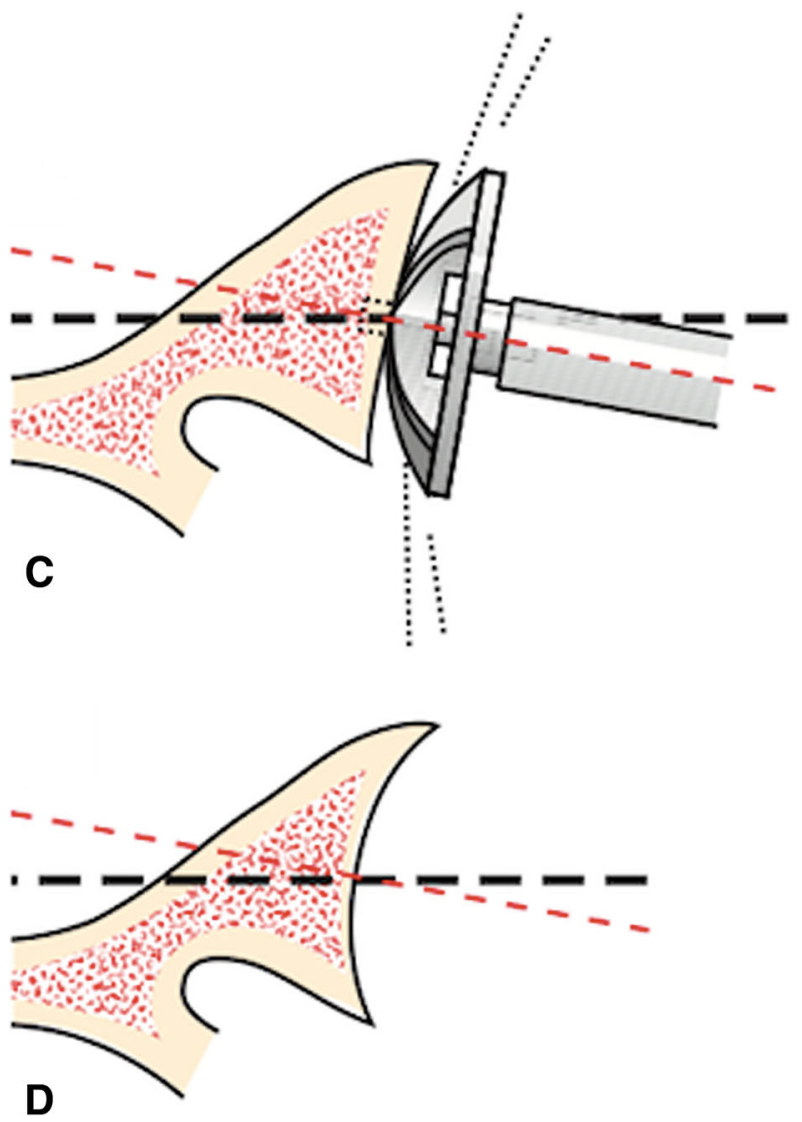
Fig. 3 In the absence of a guide wire, the orientation of the reamer can be adjusted to preserve glenoid bone stock. (Published with permission from Elsevier from Matson FA 3rd, Lippitt SB, Rockwood CA Jr, Wirth MA. Glenohumeral arthritis and its management. Rockwood and Matsen's The Shoulder, 5th Edition. 2016:831-1042.)
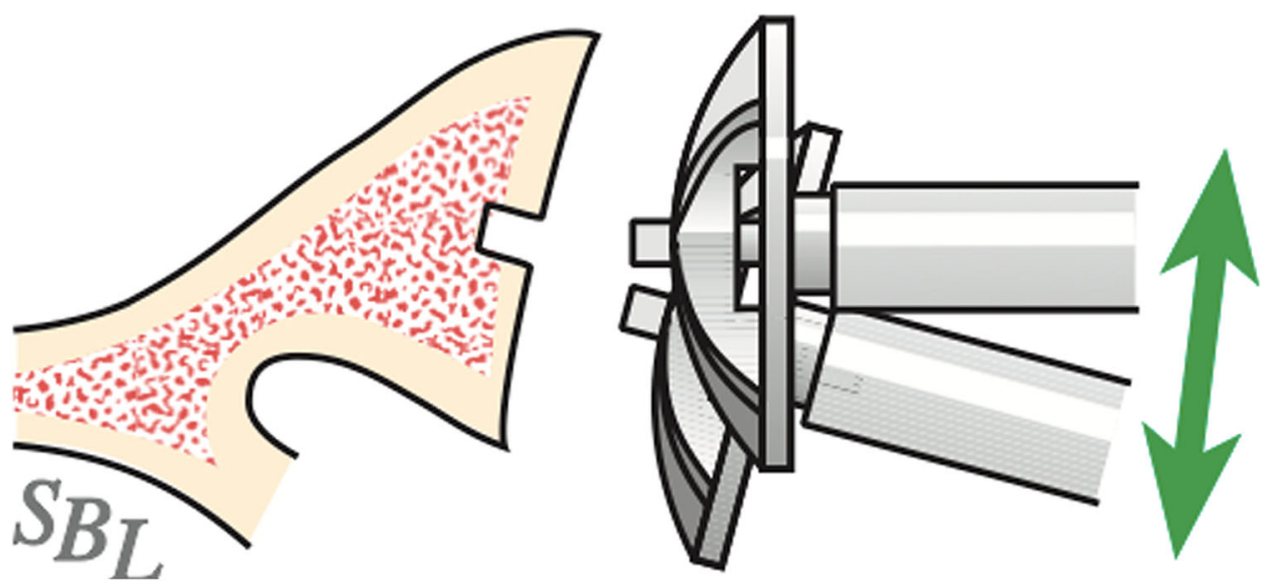
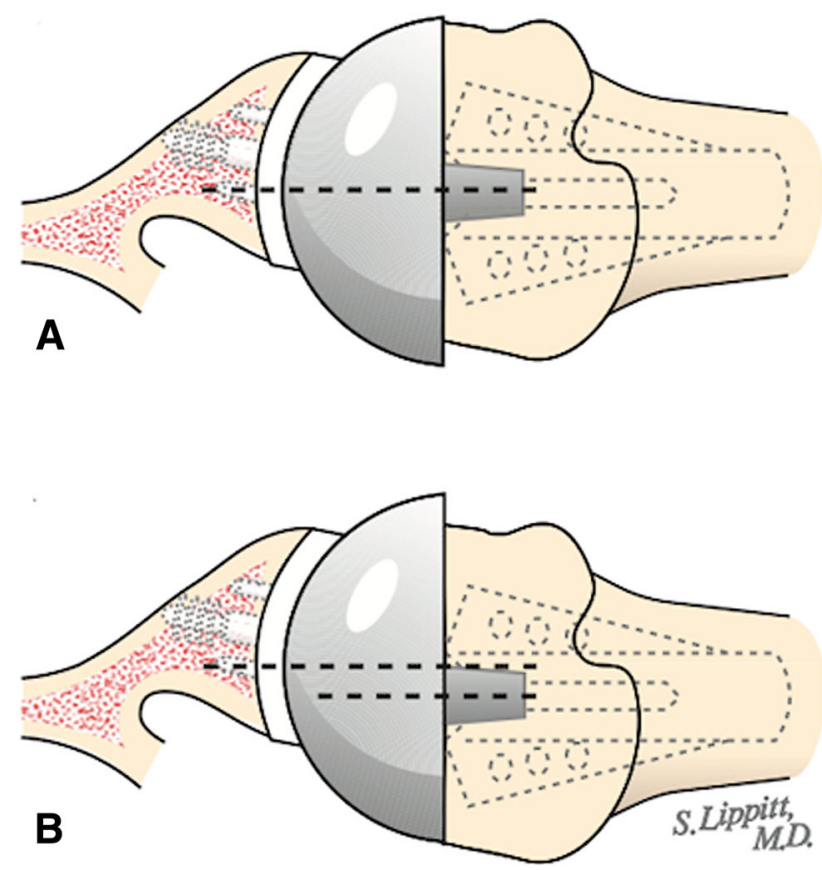

Fig. 4A-B (A) The reconstructed joint with the glenoid component inserted in retroversion is often stable with a standard humeral component in place. (B) If the standard humeral head trial component shows excessive posterior translation, an anteriorly eccentric humeral head can be used. (Published with permission from Elsevier from Matson FA 3rd, Lippitt SB, Rockwood CA Jr, Wirth MA. Glenohumeral arthritis and its management. Rockwood and Matsen's The Shoulder, 5th Edition. 2016:831-1042.)

on the radiograph obtained at the 2-year followup as the percent of the humeral head posterior to a line perpendicular to the midpoint of the glenoid face (Fig. 9) [19]. We use the term 'decentering' of the humeral head with respect to the glenoid fossa to avoid confusion with the term 'subluxation' which often is used to refer to the relationship of the humeral head to the plane of the scapula [45].

Radiolucencies around the glenoid component have been linked to inferior clinical results [4, 8, 12, 24, 38, 65] and have been associated with glenoid components implanted in retroversion [17]. Central peg lucency was measured as described by Wirth et al. [61] and Ho et al. [17]: Grade 1 indicates substantial osteolysis around the central peg, Grade 2 indicates bone integration to the edges of the flanges, and Grade 3 indicates bone integration in the flanges. We defined Grade 1 as central peg radiolucency and Grades 2 and 3 as no central peg radiolucency. The Lazarus' classification of glenoid component radiolucencies also was assessed [25]: Grade 0 is no radiolucency; Grade 1 is incomplete radiolucency around one or two pegs; Grade 2 is complete radiolucency less than $2 \mathrm{~mm}$ around one peg; Grade 3 is complete radiolucency less than $2 \mathrm{~mm}$ around two or more pegs; Grade 4 is complete radiolucency more than $2 \mathrm{~mm}$ around two or more pegs; and Grade 5 is gross loosening of the glenoid component.

\section{Revision Surgery}

The longitudinally maintained database was reviewed for evidence that patients had undergone any subsequent procedures to the affected shoulder. These data were updated at yearly clinic visits or as part of regularly mailed questionnaires that specifically asked about revision surgery. Potential indications for revision surgery included infection, symptomatic loosening, subscapularis failure, or progressive pain and stiffness that were refractory to conservative management.

\section{Statistical Analysis}

Descriptive statistics were used to characterize the patient demographics; means and SDs were presented for continuous variables, and frequencies were tabulated for categorical variables. The primary outcome variable was the preoperative to postoperative change in the SST score. 

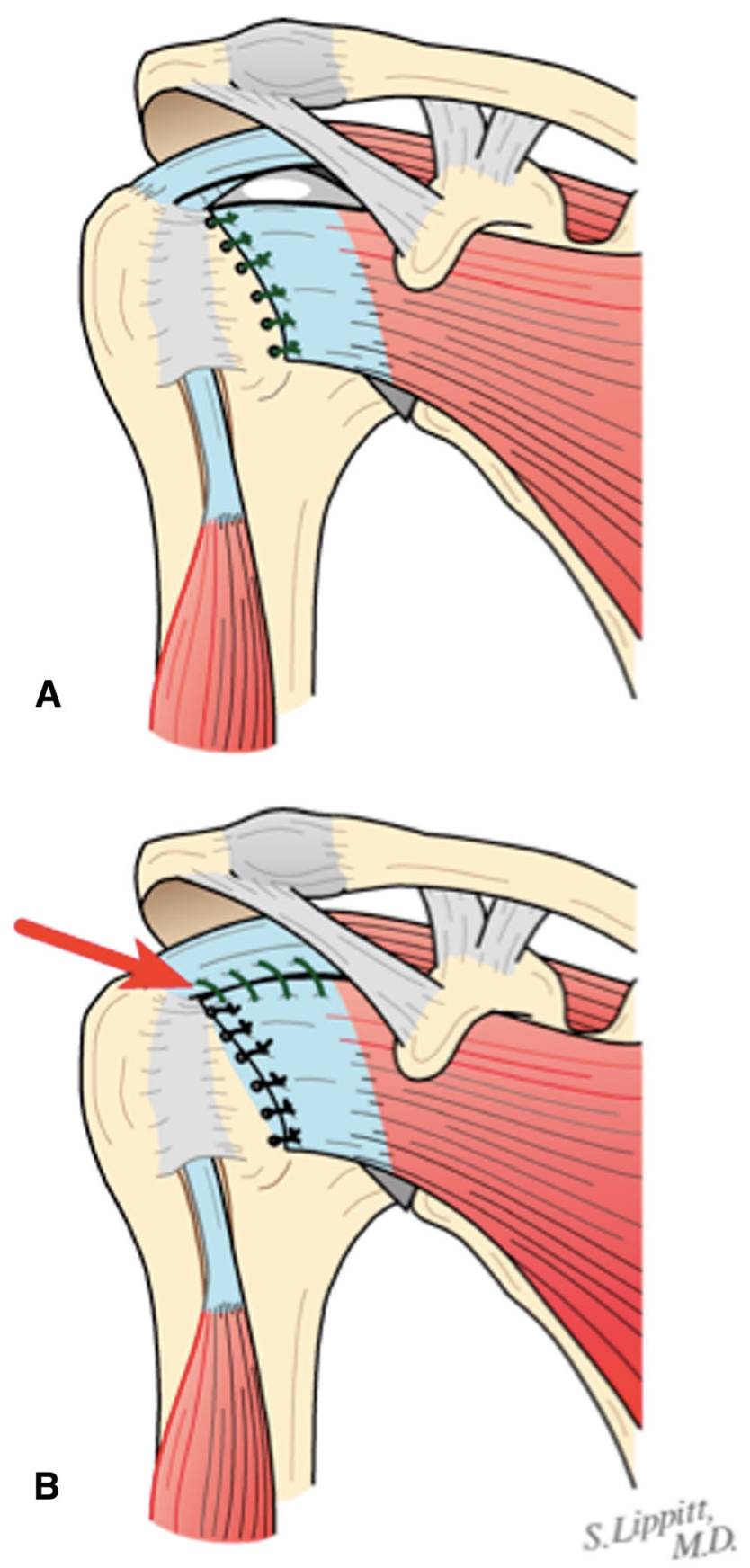

Fig. 5A-B (A) A standard subscapularis repair without rotator interval plication is shown. (B) If additional posterior stability was needed, the rotator interval was plicated by closing the upper edge of the subscapularis to the anterior edge of the supraspinatus. (Published with permission from Elsevier from Matson FA 3rd, Lippitt SB, Rockwood CA Jr, Wirth MA. Glenohumeral arthritis and its management. Rockwood and Matsen's The Shoulder, 5th Edition. 2016:831-1042.)

Roy et al. [42] suggested that the minimal clinically important difference for the SST in shoulder arthroplasty is 3. Others have suggested that the minimal clinically important difference is $30 \%$ of the MPI from preoperative to latest followup [11, 31, 48].

Shoulders in which the glenoid component was implanted in $15^{\circ}$ or greater retroversion (retroverted) were compared with shoulders in which the glenoid component was implanted in less than $15^{\circ}$ retroversion (nonretroverted). The cutoff of $15^{\circ}$ was selected based on previous studies suggesting less than $15^{\circ}$ retroversion was required for acceptable joint biomechanics and for the use of a standard polyethylene component; implanting a glenoid component in $15^{\circ}$ or greater retroversion has been thought to be associated with inferior outcomes [3, 6, 10, 17, 47]. Significance testing was performed using a standard twotailed t-test for continuous variables and Fisher's exact, Mann-Whitney U, Wilcoxon signed rank, and chi-square tests for categorical variables. Significance was set as a probability less than 0.05 .

To address the potential for transfer bias, we compared the demographics and postoperative outcomes for the 71 patients included in the study with the 22 who did not have radiographs adequate for making the necessary measurements. The majority of these unusable radiographs were obtained at centers near the homes of patients unable to return to our center, where our technologists have established a standard and highly reproducible shoulder x-ray protocol. We found that the 22 excluded patients did not have substantially different mean age, sex distribution, time of followup, distribution of diagnoses, American Society of Anesthesiologists class, alcohol use, smoking history, BMI, or history of prior surgery from the 71 included in the analysis (Appendix 1. Supplemental material is available with the online version of $C O R R^{\circledR}$.). Preoperative retroversion measurements were available for 11 of the 22 excluded patients. For these 11 shoulders, the mean $( \pm \mathrm{SD})$ retroversion was $15.8^{\circ} \pm 14.6^{\circ}$, five of the 11 $(45 \%)$ had less than $15^{\circ}$, and six of the $11(55 \%)$ had $15^{\circ}$ or more retroversion.

Seventy-one shoulders were included in the final analysis, including 21 in the retroverted group and 50 in the nonretroverted group (Table 1). The retroverted group had two factors that might have contributed to inferior results: a higher percentage of patients who had undergone prior surgeries and a longer average followup than patients in the nonretroverted group.

Because of the commonly expressed concern regarding management of the type B glenoid-a glenohumeral pathomorphology characterized by posterior humeral decentering with or without a glenoid surface biconcavity, we performed a subgroup analysis of the clinical and radiographic results for the 39 type $\mathrm{B}$ glenoids in this series, 15 of which were retroverted and 24 of which were nonretroverted. 
Table 1. Patient demographics and shoulder characteristics

\begin{tabular}{|c|c|c|c|c|}
\hline Variable & All patients $(\mathrm{n}=71)$ & Retroverted $(\mathrm{n}=21)$ & Nonretroverted $(\mathrm{n}=50)$ & $\mathrm{p}$ Value \\
\hline Age (years, mean $\pm \mathrm{SD}$ ) & $68 \pm 8.3$ & $66 \pm 10$ & $69 \pm 8$ & 0.219 \\
\hline $\operatorname{Sex}(\mathrm{n}, \%$ male $)$ & $34(48 \%)$ & $8(38 \%)$ & $26(52 \%)$ & 0.284 \\
\hline Followup (years, mean \pm SD) & $2.5 \pm 0.6$ & $3.2 \pm 0.5$ & $2.2 \pm 0.3$ & $<0.001$ \\
\hline \multicolumn{5}{|l|}{ Diagnosis } \\
\hline Osteoarthritis (n, \%) & $61(86 \%)$ & $15(71 \%)$ & $46(92 \%)$ & \multirow[t]{4}{*}{0.139} \\
\hline Posttraumatic arthritis (n, \%) & $3(4 \%)$ & $2(10 \%)$ & $1(2 \%)$ & \\
\hline Capsulorrhaphy arthropathy (n, \%) & $3(4 \%)$ & $2(10 \%)$ & $1(2 \%)$ & \\
\hline Other $(\mathrm{n}, \%)$ & $4(6 \%)$ & $2(10 \%)$ & $2(4 \%)$ & \\
\hline \multicolumn{5}{|l|}{ ASA classification } \\
\hline 1 & $2(3 \%)$ & $0(0 \%)$ & $2(4 \%)$ & \multirow[t]{4}{*}{0.275} \\
\hline 2 & $50(70 \%)$ & $13(62 \%)$ & $37(74 \%)$ & \\
\hline 3 & $19(27 \%)$ & $8(38 \%)$ & $11(22 \%)$ & \\
\hline 4 & $0(0 \%)$ & $0(0 \%)$ & $0(0 \%)$ & \\
\hline Alcohol use (n, \%) & $47(66 \%)$ & $12(57 \%)$ & $35(70 \%)$ & 0.296 \\
\hline \multicolumn{5}{|l|}{ Smoking } \\
\hline Never $(\mathrm{n}, \%)$ & $26(37 \%)$ & $9(43 \%)$ & $17(34 \%)$ & \multirow[t]{3}{*}{0.208} \\
\hline Quit (n, \%) & $44(62 \%)$ & $11(52 \%)$ & $33(66 \%)$ & \\
\hline Current (n, \%) & $1(1 \%)$ & $1(5 \%)$ & $0(0 \%)$ & \\
\hline $\mathrm{BMI}($ mean $\pm \mathrm{SD})$ & $30 \pm 7$ & $32 \pm 7$ & $29 \pm 7$ & 0.078 \\
\hline Prior surgery $(\mathrm{n}, \%)$ & $18(25 \%)$ & $9(43 \%)$ & $9(18 \%)$ & 0.028 \\
\hline Preoperative glenoid version* (degrees, mean \pm SD) & $13.6^{\circ} \pm 11.9^{\circ *}$ & $21.1^{\circ} \pm 9.9^{\circ}$ & $9.7^{\circ} \pm 11.1^{\circ}$ & 0.001 \\
\hline Preoperative decentering $* *(\%$, mean \pm SD $)$ & $7.2 \% \pm 8.3 \%$ & $11.1 \% \pm 8.3 \%$ & $5.5 \% \pm 7.7 \%$ & 0.031 \\
\hline \multicolumn{5}{|l|}{ Glenoid type [37] } \\
\hline $\mathrm{A} 1^{\dagger}$ & $10(14 \%)$ & $1(5 \%)$ & $9(18 \%)$ & \multirow[t]{4}{*}{0.184} \\
\hline $\mathrm{A} 2^{*}$ & $22(31 \%)$ & $5(24 \%)$ & $17(34 \%)$ & \\
\hline $\mathrm{B} 1^{\S}$ & $14(20 \%)$ & $4(19 \%)$ & $10(20 \%)$ & \\
\hline $\mathrm{B} 2$ & $25(35 \%)$ & $11(52 \%)$ & $14(28 \%)$ & \\
\hline
\end{tabular}

ASA $=$ American Society of Anesthesiologists; *preoperative version ranged from $38.8^{\circ}$ retroversion to $10.9^{\circ}$ anteversion; **preoperative decentering ranged from $27 \%$ posterior decentering to $18 \%$ anterior decentering; 'humeral head centered on the glenoid without posterior subluxation with minor erosion; "humeral head centered on the glenoid with major erosion; ${ }^{\S}$ humeral head posteriorly subluxated on the glenoid without posterior glenoid erosion; "humeral head posteriorly subluxated on the glenoid with posterior glenoid erosion.

\section{Results}

With the numbers available, the mean $( \pm \mathrm{SD})$ improvement in the SST $(6.7 \pm 3.6$; from $2.6 \pm 2.6$ to $9.3 \pm 2.9)$ for the retroverted group was not inferior to that for the nonretroverted group $(5.8 \pm 3.6$; from $3.7 \pm 2.5$ to $9.4 \pm$ 3.0) (Table 2). Although the 2-year SST scores are similar, the preoperative scores for the retroverted glenoids were $2.6 \pm 2.6$ compared with $3.7 \pm 2.5$ for the nonretroverted glenoids. The mean difference in improvement between the two groups was $0.9(95 \% \mathrm{CI},-2.5$ to $0.7 ; \mathrm{p}=0.412)$.

The \%MPI for the retroverted glenoids $(70 \% \pm 31 \%)$ was not inferior to that for the nonretroverted glenoids $(67 \% \pm 44 \%)$. The mean difference between the two groups was $3 \%(95 \% \mathrm{CI},-18 \%$ to $12 \% ; \mathrm{p}=0.857)$.
The 2-year SST scores for the retroverted $(9.3 \pm 2.9)$ and the nonretroverted glenoids $(9.4 \pm 3.0)$ were similar (mean difference, $0.2 ; 95 \% \mathrm{CI},-1.1$ to $1.4 ; \mathrm{p}=0.697$ ).

The longitudinally maintained database contained no indication of subluxation or dislocation for patients in either group.

With the numbers available, the radiographic results for the retroverted glenoids were similar to those for the nonretroverted glenoids with respect to central peg lucency (four of 21 [19\%] versus six of 50 [12\%]; $p=0.436$; odds ratio, 1.7; 95\% CI, 0.4-6.9), average Lazarus radiolucency scores $(0.5$ versus 0.7 , Mann Whitney $\mathrm{p}$ value $=0.873$; Wilcoxon rank sum test $\mathrm{W}=512$, $\mathrm{p}$ value $=0.836$ ), and the mean percentage of posterior humeral head decentering $(3.4 \% \pm 5.5 \%$ versus $1.6 \% \pm 6.0 \% ; \mathrm{p}=0.223)$ (Table 3$)$. 


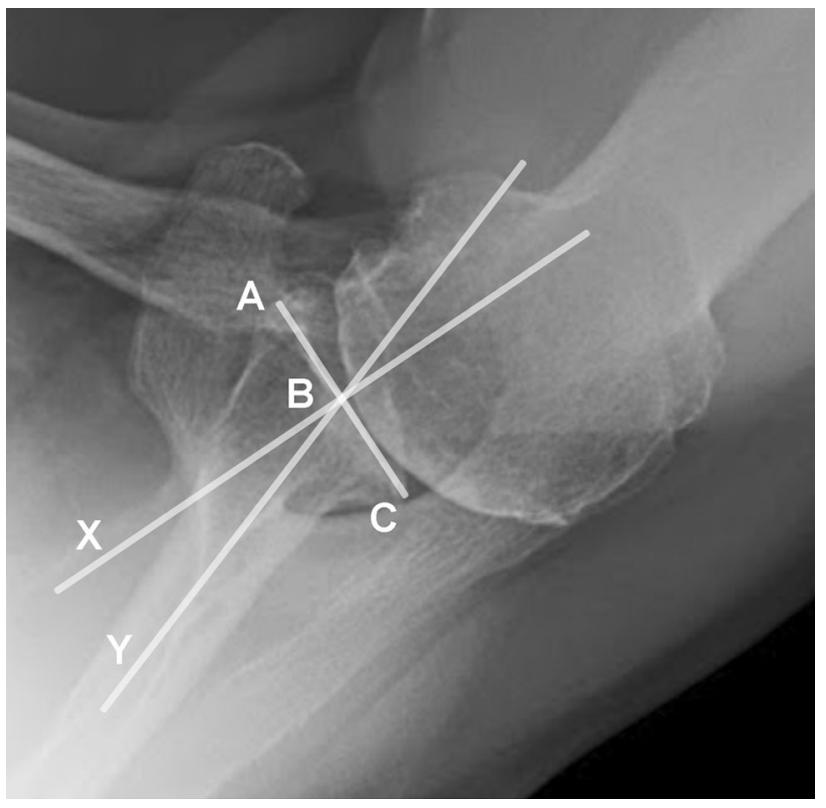

Fig. 6 The radiographic measurement of preoperative glenoid version is shown. A line segment is drawn connecting the anterior (A) and posterior $(\mathrm{C})$ edges of the glenoid. Line $\mathrm{B}-\mathrm{X}$ is the perpendicular bisector of this line segment (the glenoid centerline). Line B-Y is drawn along the plane of the scapula. The angle between B-X and B$\mathrm{Y}$ is the glenoid retroversion.

With the numbers available, the percentage of patients with retroverted glenoids undergoing revision (0 of 21 [0\%]) was not inferior to the percentage for patients with nonretroverted glenoids (three of $50[6 \%] ; \mathrm{p}=0.251$ ).

\section{Type B Glenoids}

The improvement in SST for the retroverted type B glenoids $(7.8 \pm 2.9)$ was not inferior to improvement for the nonretroverted type B glenoids $(5.3 \pm 3.1 ; \mathrm{p}=0.023)$ (Table 4). The \%MPI was not worse for the retroverted type B glenoids $(80 \% \pm 22 \%)$ than for the nonretroverted type B glenoids $(68 \% \pm 35 \%)$. These findings may be attributable to the lower preoperative SST scores for the retroverted type B glenoids $(2.2 \pm 2.3)$ in comparison to the nonretroverted type B glenoids $(3.9 \pm 2.5 ; \mathrm{p}=0.039)$.

As expected, component retroversion for the retroverted glenoids $\left(20.9^{\circ} \pm 5.6^{\circ}\right)$ was greater than that for the nonretroverted glenoids $\left(7.3^{\circ} \pm 6.1^{\circ} ; \mathrm{p}<0.001\right)$; similarly central peg perforation was more frequent for the retroverted glenoids (eight of 15 [53\%]) in comparison to the nonretroverted glenoids (four of $24[17 \%] ; p=0.016$ ); however, with the numbers available the radiographic results were not statistically significantly different between the two groups with respect to central peg lucency, Lazarus grading, or posterior decentering.

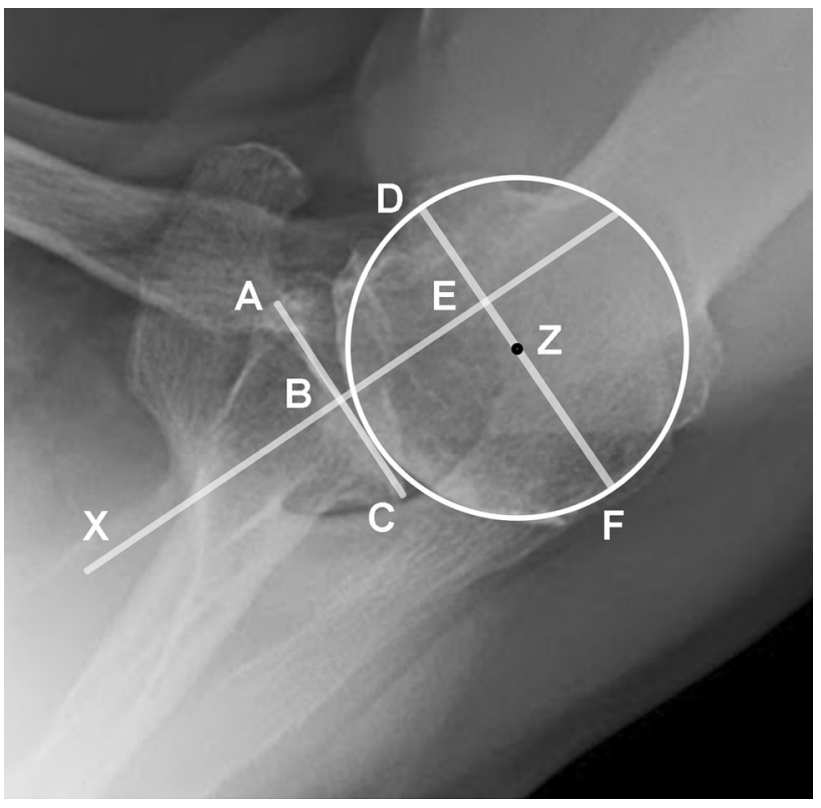

Fig. 7 The radiographic measurement of preoperative posterior decentering is shown. It is expressed as the percent of the humeral head circle lying behind the glenoid centerline on the standardized axillary view taken with the arm in the functional position of elevation in the plane of the scapula. The humeral head circle is drawn with point $\mathrm{Z}$ marking the center of this circle. A line segment is drawn connecting the anterior (A) and posterior (C) edges of the glenoid. Line B-X is the perpendicular bisector of this line segment (the glenoid centerline). Line segment D-F marks the diameter of the humeral head circle drawn parallel to line segment A-C. Point E marks the intersection between D-F and B-X. The percentage of the humeral head circle lying behind the glenoid centerline is calculated as $(\mathrm{E}-\mathrm{Z}) /(\mathrm{D}-\mathrm{F}) \times 100 \%$

\section{Revisions}

The percentage of TSAs revised was not worse for the retroverted glenoids ( 0 of $21[0 \%]$ ) than the percentage for the nonretroverted glenoids (three of 10 [6\%]). In the nonretroverted group, one patient had a revision with humeral head exchange for stiffness 3.5 months after the initial arthroplasty, and a second patient underwent subscapularis repair and exchange of the humeral components after a fall that caused subscapularis failure just over 2 months after the index procedure. The third patient had a subscapularis reconstruction with allograft tendon after traumatic failure occurring 25 months after the index operation.

\section{Discussion}

Authors have expressed concern regarding inferior clinical outcomes when standard glenoid components are inserted in more than $15^{\circ}$ retroversion, leading surgeons to seek 


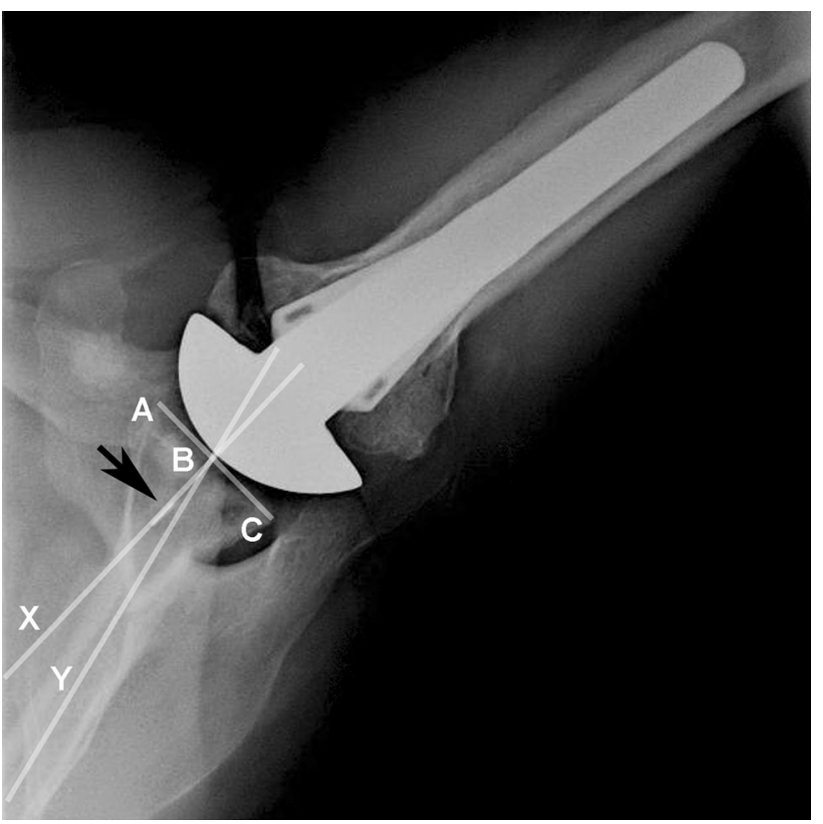

Fig. 8 The radiographic measurement of postoperative glenoid component version is shown. A line segment is drawn connecting the anterior (A) and posterior (C) edges of the glenoid component with point $\mathrm{B}$ bisecting the line between $\mathrm{A}$ and $\mathrm{C}$. Line $\mathrm{B}-\mathrm{X}$, the glenoid component centerline, is drawn along the metal marker in the central peg of the glenoid component (black arrow). Line B-Y is drawn along the plane of the scapular body. The angle between these two lines is glenoid component retroversion.

approaches for changing glenoid version in TSAs $[5,7,10,16,21,34,40,44,49,59]$. While arthritic shoulders with substantial preoperative retroversion represent a more-severe form of glenohumeral arthritis, it remains unclear whether, as suggested by some authors $[3,6,10,17,47]$, the clinical results of inserting a standard glenoid component in $15^{\circ}$ or more retroversion are inferior to those obtained when the glenoid component is inserted in less than $15^{\circ}$ retroversion. In an attempt to answer this question we sought to determine if the clinical results of retroverted glenoids were worse than those for nonretroverted glenoids in a series of TSAs in which the glenoid component was inserted without attempting to change glenoid version. With the numbers available, the clinical results were not worse for the patients with retroverted glenoids.

There are several limitations to our study. First, while the clinical results for patients with retroverted glenoids were not worse than those for patients with nonretroverted glenoids in this series, it is possible that a larger series might have yielded different results. Second, progressive glenoid component lucency and failure may occur many years after implantation; our 2-year results may not presage the long-term outcomes of these TSAs [57, 58]. Further evaluation of these patients at 5 and 10 years

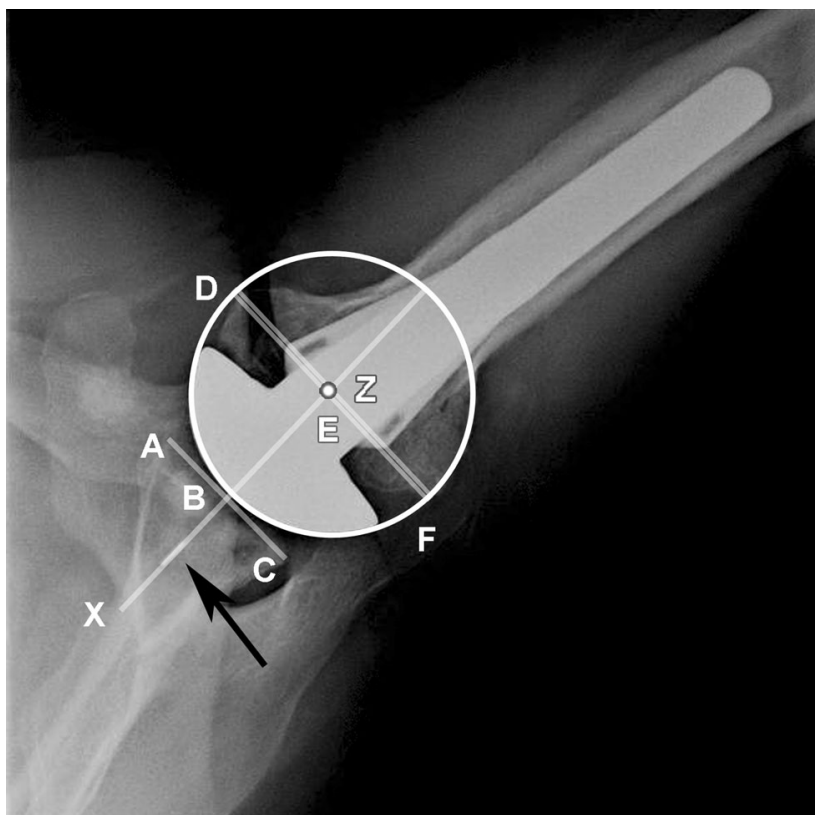

Fig. 9 The radiographic measurement of postoperative posterior decentering is shown. It is expressed as the percent of the humeral head circle lying behind the centerline of the glenoid component on the standardized axillary view taken with the arm in the functional position of elevation in the plane of the scapula. The humeral head circle is drawn with point $\mathrm{Z}$ marking the center of this circle. Line $\mathrm{B}$ $\mathrm{X}$, the glenoid component centerline, is drawn along the metal marker in the central peg of the glenoid component (black arrow). Line segment D-F marks the diameter of the humeral head circle perpendicular to the glenoid centerline with point $\mathrm{E}$ marking the intersection between D-F and B-X. The percentage of the humeral head circle lying behind the glenoid centerline is calculated as (E-Z)/ (D-F) $x \quad 100 \%$. A centered humeral head with $0 \%$ posterior decentering is shown in this figure.

postoperatively would provide greater certainty in answering whether the clinical results of glenoid components inserted in $15^{\circ}$ or more retroversion became inferior with time to those inserted in less than $15^{\circ}$ retroversion. Third, while the preoperative to postoperative changes in the SST scores were $6.7 \pm 3.6$ for the retroverted glenoid group and $5.8 \pm 3.6$ for the nonretroverted glenoid group, our study was not intended to nor sufficiently powered to assess a minimal clinically important difference ( 3 points in the SST score) between the retroverted and nonretroverted groups. Fourth, we relied on standardized axillary views to determine the preoperative and postoperative glenoid version and glenohumeral relationships. Although some authors point to greater precision with CT scans in the measurement of preoperative glenoid pathoanatomy [36], the advantages of standardized axillary views are that they are less expensive, administer a lower radiation dose, and enable comparison of preoperative and postoperative glenoid version and glenohumeral relationships. The degree of agreement between $\mathrm{CT}$ and plain radiographic 
Table 2. Clinical outcomes

\begin{tabular}{|c|c|c|c|c|c|}
\hline Variable & $\begin{array}{l}\text { All patients }(\mathrm{n}=71) \\
(\text { mean } \pm \mathrm{SD})\end{array}$ & $\begin{array}{l}\text { Retroverted }(\mathrm{n}=21) \\
(\text { mean } \pm \mathrm{SD})\end{array}$ & $\begin{array}{l}\text { Nonretroverted }(\mathrm{n}=50) \\
(\text { mean } \pm \mathrm{SD})\end{array}$ & $\begin{array}{l}\text { Mean difference }(95 \% \mathrm{CI}) \text {, } \\
\text { relative risk }(\mathrm{CI})\end{array}$ & $\mathrm{p}$ Value \\
\hline \multicolumn{6}{|c|}{ Simple Shoulder Test (mean \pm SD) } \\
\hline Preoperative score & $3.4 \pm 2.5$ & $2.6 \pm 2.6$ & $3.7 \pm 2.5$ & $1.0(-0.1$ to 2.2$)$ & 0.127 \\
\hline 2-year score & $9.4 \pm 2.9$ & $9.3 \pm 2.9$ & $9.4 \pm 3.0$ & $0.2(-1.1$ to 1.4$)$ & 0.842 \\
\hline Change in score & $6.0 \pm 3.5$ & $6.7 \pm 3.6$ & $5.8 \pm 3.6$ & $-0.9(-2.5$ to 0.7$)$ & 0.349 \\
\hline$\%$ MPI $($ mean \pm SD) & $68 \% \pm 40 \%$ & $70 \% \pm 31 \%$ & $67 \% \pm 44 \%$ & $-3 \%(-18 \%$ to $12 \%)$ & 0.737 \\
\hline
\end{tabular}

$\%$ MPI = percent maximum possible improvement.

Table 3. Radiographic outcomes

\begin{tabular}{|c|c|c|c|c|}
\hline Variable & All patients $(\mathrm{n}=71)$ & Retroverted $(\mathrm{n}=21)$ & Nonretroverted $(\mathrm{n}=50)$ & $\mathrm{p}$ Value \\
\hline Component retroversion (degrees; mean $\pm \mathrm{SD}$ ) & $10.2 \pm 9.5$ & $20.7 \pm 5.3$ & $5.7 \pm 6.9$ & $<0.001$ \\
\hline Central peg lucency* & $10(14 \%)$ & $4(19 \%)$ & $6(12 \%)$ & 0.436 \\
\hline \multicolumn{5}{|l|}{ Lazarus radiolucency** } \\
\hline 0 & $51(72 \%)$ & $15(71 \%)$ & $36(72 \%)$ & \multirow[t]{6}{*}{0.237} \\
\hline 1 & $6(8 \%)$ & $2(10 \%)$ & $4(8 \%)$ & \\
\hline 2 & $7(10 \%)$ & $4(19 \%)$ & $3(6 \%)$ & \\
\hline 3 & $6(8 \%)$ & $0(0 \%)$ & $6(12 \%)$ & \\
\hline 4 & $0(0 \%)$ & $0(0 \%)$ & $0(0 \%)$ & \\
\hline 5 & $1(1 \%)$ & $0(0 \%)$ & $1(2 \%)$ & \\
\hline Posterior decentering (mean $\pm \mathrm{SD}$ ) & $2.1 \% \pm 5.9 \%$ & $3.4 \% \pm 5.5 \%$ & $1.6 \% \pm 6.0 \%$ & 0.223 \\
\hline Central peg perforation & $20(28 \%)$ & $11(52 \%)$ & $9(18 \%)$ & 0.003 \\
\hline
\end{tabular}

measurements of glenoid version has been documented [18]. Fifth, Yian et al. [63] reported that postoperative CT scans are more sensitive to postoperative radiolucencies. Interestingly they reported that at a mean of 40 months after surgery there was no effect of glenoid retroversion on radiographic loosening or lucencies detected by CT scans [63]. The use of standardized radiographs for assessment of periglenoid lucency generally has been accepted $[17,25,49]$. Sixth, we excluded 22 patients $(24 \%$ of the 93 otherwise eligible patients with 2-year clinical followup and 2-year postoperative radiographs) who did not have adequate pre- or postoperative radiographs for measuring all radiographic variables. The majority of these unacceptable radiographs were obtained at centers near the homes of patients unable to return to our office for standardized films. It is possible that this may have introduced a bias, although the preoperative characteristics of the included and excluded shoulders appeared to be similar. Seventh, the patients with retroverted glenoids were different in some respects than those with nonretroverted glenoids in that the former had lower preoperative SST scores, a higher percentage of prior surgery, and longer followup than the nonretroverted group; despite these potentially adverse factors, the clinical results for the retroverted glenoid group were not worse than for the nonretroverted glenoid group. Eighth, the patients in our study were cared for at a tertiary shoulder practice; therefore, these results may not be generalizable to other settings. Ninth, this study does not compare our approach with alternative methods of managing glenoid retroversion, such as eccentric reaming, posterior bone grafting, posteriorly augmented glenoid components, or reverse TSA.

With the numbers available, we found that the clinical results for shoulders with glenoid components inserted in $15^{\circ}$ or greater retroversion were not worse than those for components inserted in less than $15^{\circ}$ retroversion. Our results can be compared with those of Ho et al. [17], who examined the precept that glenoid component retroversion and eccentric loading can lead to glenoid component loosening. They reviewed 66 shoulders having total shoulder replacement with an all-polyethylene press-fit pegged glenoid component similar to that used in our study. At an average of $3.8 \pm 1.8$ years after surgery, 20 had osteolysis around the center peg on plain radiographs. The length of time after replacement, preoperative glenoid retroversion, and postoperative glenoid component retroversion were correlated with osteolysis around the glenoid center peg and an increase in the Lazarus component 
Table 4. Clinical and radiographic results in Type B glenoids

\begin{tabular}{|c|c|c|c|c|c|}
\hline Variable & $\begin{array}{l}\text { Type B glenoids } \\
(\mathrm{n}=39)\end{array}$ & $\begin{array}{l}\text { Retroverted } \\
(\mathrm{n}=15)\end{array}$ & $\begin{array}{l}\text { Nonretroverted } \\
(\mathrm{n}=24)\end{array}$ & $\begin{array}{l}\text { Mean difference }(95 \% \mathrm{CI}) \text {, } \\
\text { relative risk }(\mathrm{CI})\end{array}$ & $\mathrm{p}$ Value \\
\hline \multicolumn{6}{|l|}{ Simple Shoulder Test (mean \pm SD) } \\
\hline Preoperative score & $3.2 \pm 2.5$ & $2.2 \pm 2.3$ & $3.9 \pm 2.5$ & $1.7(0.4$ to 3.0$)$ & 0.039 \\
\hline 2-year score & $9.5 \pm 3.0$ & $10.0 \pm 2.4$ & $9.2 \pm 3.4$ & $-0.8(-2.4$ to 0.8$)$ & 0.400 \\
\hline Change in score & $6.3 \pm 3.3$ & $7.8 \pm 2.9$ & $5.3 \pm 3.1$ & $-2.5(-4.1$ to -0.8$)$ & 0.018 \\
\hline$\%$ MPI & $73 \% \pm 31 \%$ & $80 \% \pm 22 \%$ & $68 \% \pm 35 \%$ & $-12 \%(-27 \%$ to $3 \%)$ & 0.193 \\
\hline Revision surgery & $3(7.7 \%)$ & $0(0 \%)$ & $3(12.5 \%)$ & & 0.154 \\
\hline Glenoid retroversion (degrees, mean $\pm \mathrm{SD}$ ) & $12.5 \pm 8.9$ & $20.9 \pm 5.6$ & $7.3 \pm 6.1$ & $-13.6(-16.9$ to -10.4$)$ & $<0.001$ \\
\hline Central peg lucency $[14,53]$ & $4(10 \%)$ & $3(20 \%)$ & $1(4.2 \%)$ & & 0.113 \\
\hline Lazarus radiolucency (mean \pm SD) [20] & $0.5 \pm 0.9$ & $0.5 \pm 0.8$ & $0.5 \pm 1.0$ & $0.0(-0.5$ to 0.5$)$ & 0.978 \\
\hline 0 & $30(77 \%)$ & $11(73 \%)$ & $19(79 \%)$ & & 0.500 \\
\hline 1 & $2(5 \%)$ & $1(7 \%)$ & $1(4 \%)$ & & \\
\hline 2 & $5(13 \%)$ & $3(20 \%)$ & $2(8 \%)$ & & \\
\hline 3 & $2(5 \%)$ & $0(0 \%)$ & $2(8 \%)$ & & \\
\hline 4 & $0(0 \%)$ & $0(0 \%)$ & $0(0 \%)$ & & \\
\hline 5 & $0(1 \%)$ & $0(0 \%)$ & $0(0 \%)$ & & \\
\hline Posterior decentering (mean \pm SD) & $2.9 \% \pm 6.3 \%$ & $4.2 \% \pm 6.3 \%$ & $2.1 \% \pm 6.3 \%$ & $-2.1 \%(-5.5 \%$ to $1.4 \%)$ & 0.327 \\
\hline Central peg perforation & $12(31 \%)$ & $8(53 \%)$ & $4(17 \%)$ & & 0.016 \\
\hline
\end{tabular}

\%MPI = maximum possible improvement; central peg lucency measured as described by Wirth et al. [61] and Ho et al. [17]; ** Lazarus glenoid component radiolucencies reported as previously described [25]; ***postoperative glenoid version was measured as the angle between the scapular body plane and a line through the metal marker of the central peg.

loosening grade. After adjustment for followup time, postoperative glenoid retroversion $15^{\circ}$ or greater was associated with increased odds of osteolysis (odds ratio, 5.23; 95\% CI, 1.31-20.9). Ho et al. [17] had a similar percentage of glenoids with $15^{\circ}$ or more retroversion $(22$ of $66[33 \%])$ as we had (21 of 71 [30\%]). However, while the imaging techniques appear to be similar, the overall percentage of central peg osteolysis in their study (20 of 66 [30\%]) was substantially greater than ours (10 of 71 [14\%]). In their study, the presence of osteolysis around the center peg was not correlated with a worse clinical outcome defined by shoulder scores or a reoperation attributable to glenoid loosening.

The rate of glenoid radiolucencies in our study is similar to those of other studies using pegged bone-ingrowth glenoid components [17, 37, 60, 61]. Wirth et al. [61] reported that of 44 shoulders with a mean radiographic followup of 3 years, three glenoids had Grade 1 radiolucency around the central peg (7\%). At a mean 3.9 years, Wijeratna et al. [60] reported that 10 of 83 shoulders (12\%) had osteolysis around the central peg. Parks et al. [37] studied 80 glenoid components and found $12 \%$ Grade 1 radiolucencies around the central peg at an average radiographic followup of 2.8 years. As would be expected, anterior glenoid vault perforation by the central fluted peg occurred frequently when the glenoid component was inserted in retroversion. Prior studies have shown that central peg perforation was not associated with inferior clinical or radiographic outcomes [20, 39].

Two recent studies using posteriorly augmented glenoid components showed similar radiographic findings to those of our study in which standard glenoid components were used, although the approaches to measuring glenoid retroversion were not exactly the same. Favorito et al. [7] reported on 22 TSAs using an all-polyethylene posteriorly augmented stepped glenoid component for shoulders with greater than $15^{\circ}$ retroversion. We had 21 shoulders with $15^{\circ}$ or more retroversion. The mean Lazarus radiolucency scores were 0.50 in the study by Favorito et al. compared with 0.48 in our study.

Stephens et al. [49] reported results of posteriorly augmented glenoids in shoulders with preoperative retroversion averaging $20.8^{\circ}$. Postoperative retroversion averaged $9^{\circ}$. Radiolucencies surrounding the glenoid were found in five of 21, of which four were Grade 1 and one was Grade 2 [49].

The percentage of patients in our study who underwent any subsequent surgery was $6 \%$ in the nonretroverted group and none in the retroverted group. None of these subsequent surgeries were performed owing to glenoid loosening. There were no known postoperative episodes of instability. These results are similar to those of Stephens 
et al. [49] with posteriorly augmented components, in which there were no reported glenoid component failures. However, Favorito et al. [7] reported two postoperative dislocations using posteriorly augmented components. One patient had an anterior dislocation noted at the first postoperative evaluation 2 weeks after the index procedure resulting in revision surgery. The second patient sustained a posterior dislocation 22 months postoperatively that was treated with revision to a reverse TSA.

\section{Conclusion}

In this small series of TSAs with conservative glenoid reaming without a specific attempt to correct glenoid retroversion, the 2-year results of shoulders with retroverted glenoid components were not inferior to those for shoulders with nonretroverted glenoids; there were no revisions in the patients with retroverted glenoids. Larger, longer-term comparative studies will be necessary to determine the maximum amount of retroversion that can be effectively managed using the approach described here and how the results of this technique compare with those of shoulder arthroplasties performed for similar pathoanatomy, for example, using eccentric reaming, posterior bone grafting, posteriorly augmented glenoid components, or reverse TSA.

Acknowledgments We thank Susan DeBartolo BA (Department of Orthopaedics and Sports Medicine, University of Washington) for editorial work

\section{References}

1. Angst F, Schwyzer HK, Aeschlimann A, Simmen BR, Goldhahn J. Measures of adult shoulder function: Disabilities of the Arm, Shoulder, and Hand Questionnaire (DASH) and its short version (QuickDASH), Shoulder Pain and Disability Index (SPADI), American Shoulder and Elbow Surgeons (ASES) Society standardized shoulder assessment form, Constant (Murley) Score (CS), Simple Shoulder Test (SST), Oxford Shoulder Score (OSS), Shoulder Disability Questionnaire (SDQ), and Western Ontario Shoulder Instability Index (WOSI). Arthritis Care Res (Hoboken). 2011;63(suppl 11):S174-188.

2. Beckmann JT, Hung M, Bounsanga J, Wylie JD, Granger EK, Tashjian RZ. Psychometric evaluation of the PROMIS Physical Function Computerized Adaptive Test in comparison to the American Shoulder and Elbow Surgeons score and Simple Shoulder Test in patients with rotator cuff disease. J Shoulder Elbow Surg. 2015;24:1961-1967.

3. Clavert P, Millett PJ, Warner JJ. Glenoid resurfacing: what are the limits to asymmetric reaming for posterior erosion? $J$ Shoulder Elbow Surg. 2007;16:843-848.

4. Collin P, Tay AK, Melis B, Boileau P, Walch G. A ten-year radiologic comparison of two-all polyethylene glenoid component designs: a prospective trial. J Shoulder Elbow Surg. 2011;20:1217-1223.
5. Denard PJ, Walch G. Current concepts in the surgical management of primary glenohumeral arthritis with a biconcave glenoid. J Shoulder Elbow Surg. 2013;22:1589-1598.

6. Farron A, Terrier A, Buchler P. Risks of loosening of a prosthetic glenoid implanted in retroversion. J Shoulder Elbow Surg. 2006;15:521-526.

7. Favorito PJ, Freed RJ, Passanise AM, Brown MJ. Total shoulder arthroplasty for glenohumeral arthritis associated with posterior glenoid bone loss: results of an all-polyethylene, posteriorly augmented glenoid component. $J$ Shoulder Elbow Surg. 2016;25:1681-1689.

8. Gazielly DF, Scarlat MM, Verborgt O. Long-term survival of the glenoid components in total shoulder replacement for arthritis. Int Orthop. 2015;39:285-289.

9. Gerber C, Costouros JG, Sukthankar A, Fucentese SF. Static posterior humeral head subluxation and total shoulder arthroplasty. J Shoulder Elbow Surg. 2009;18:505-510.

10. Gillespie R, Lyons R, Lazarus M. Eccentric reaming in total shoulder arthroplasty: a cadaveric study. Orthopedics. 2009;32:21.

11. Gilmer BB, Comstock BA, Jette JL, Warme WJ, Jackins SE, Matsen FA. The prognosis for improvement in comfort and function after the ream-and-run arthroplasty for glenohumeral arthritis: an analysis of 176 consecutive cases. J Bone Joint Surg Am. 2012;94:e102.

12. Godenèche A, Boileau P, Favard L, Le Huec JC, Lévigne C, Nové-Josserand L, Walch G, Edwards TB. Prosthetic replacement in the treatment of osteoarthritis of the shoulder: early results of 268 cases. J Shoulder Elbow Surg. 2002;11:11-18.

13. Godfrey J, Hamman R, Lowenstein S, Briggs K, Kocher M. Reliability, validity, and responsiveness of the simple shoulder test: psychometric properties by age and injury type. J Shoulder Elbow Surg. 2007;16:260-267.

14. Habermeyer P, Magosch P, Lichtenberg S. Recentering the humeral head for glenoid deficiency in total shoulder arthroplasty. Clin Orthop Relat Res. 2007;457:124-132.

15. Harryman DT 2nd, Sidles JA, Harris SL, Matsen FA 3rd. The role of the rotator interval capsule in passive motion and stability of the shoulder. J Bone Joint Surg Am. 1992;74:53-66.

16. Hill JM, Norris TR. Long-term results of total shoulder arthroplasty following bone-grafting of the glenoid. J Bone Joint Surg Am. 2001;83:877-883.

17. Ho JC, Sabesan VJ, Iannotti JP. Glenoid component retroversion is associated with osteolysis. J Bone Joint Surg Am. 2013;95:e82.

18. Ho JC, Youderian AR, Davidson IU, Bryan J, Iannotti JP. Accuracy and reliability of postoperative radiographic measurements of glenoid anatomy and relationships in patients with total shoulder arthroplasty. J Shoulder Elbow Surg. 2013;22:10681077.

19. Hsu JE, Gee AO, Lucas RM, Somerson JS, Warme WJ, Matsen FA 3rd. Management of intraoperative posterior decentering in shoulder arthroplasty using anteriorly eccentric humeral head components. J Shoulder Elbow Surg. 2016;25:1980-1988.

20. Hsu JE, Namdari S, Baron M, Kuntz AF, Abboud JA, Huffman GR, Williams GR, Glaser DL. Glenoid perforation with pegged components during total shoulder arthroplasty. Orthopedics. 2014;37:e587-591.

21. Hsu JE, Ricchetti ET, Huffman GR, Iannotti JP, Glaser DL. Addressing glenoid bone deficiency and asymmetric posterior erosion in shoulder arthroplasty. J Shoulder Elbow Surg. 2013;22:1298-1308.

22. Hsu JE, Russ SM, Somerson JS, Tang A, Warme WJ, Matsen FA 3rd. Is the Simple Shoulder Test a valid outcome instrument for shoulder arthroplasty? J Shoulder Elbow Surg. 2017 Jun 17. [Epub ahead of print]. 
23. Karelse A, Van Tongel A, Verstraeten T, Poncet D, De Wilde LF. Rocking-horse phenomenon of the glenoid component: the importance of inclination. J Shoulder Elbow Surg. 2015;24:11421148.

24. Kasten P, Pape G, Raiss P, Bruckner T, Rickert M, Zeifang F, Loew M. Mid-term survivorship analysis of a shoulder replacement with a keeled glenoid and a modern cementing technique. $J$ Bone Joint Surg Br. 2010;92:387-392.

25. Lazarus MD, Jensen KL, Southworth C, Matsen FA 3rd. The radiographic evaluation of keeled and pegged glenoid component insertion. J Bone Joint Surg Am. 2002;84:1174-1182.

26. Lewis GS, Conaway WK, Wee H, Kim HM. Effects of anterior offsetting of humeral head component in posteriorly unstable total shoulder arthroplasty: finite element modeling of cadaver specimens. J Biomech. 2017;53:78-83.

27. Lucas RM, Hsu JE, Gee AO, Neradilek MB, Matsen FA 3rd. Impaction autografting: bone-preserving, secure fixation of a standard humeral component. $J$ Shoulder Elbow Surg. 2016;25:1787-1794.

28. Matsen FA 3rd, Clinton J, Lynch J, Bertelsen A, Richardson ML. Glenoid component failure in total shoulder arthroplasty. J Bone Joint Surg Am. 2008;90:885-896.

29. Matsen FA 3rd, Gupta A. Axillary view: arthritic glenohumeral anatomy and changes after ream and run. Clin Orthop Relat Res. 2014;472:894-902.

30. Matsen FA 3rd, Lippitt SB. Current technique for the ream-andrun arthroplasty for glenohumeral osteoarthritis. JBJS Essent Surg Tech. 2012;2:e20.

31. Matsen FA 3rd, Russ SM, Vu PT, Hsu JE, Lucas RM, Comstock BA. What factors are predictive of patient-reported outcomes? A prospective study of 337 shoulder arthroplasties. Clin Orthop Relat Res. 2016;474:2496-2510.

32. Matsen FA 3rd, Warme WJ, Jackins SE. Can the ream and run procedure improve glenohumeral relationships and function for shoulders with the arthritic triad? Clin Orthop Relat Res. 2015;473:2088-2096.

33. Mizuno N, Denard PJ, Raiss P, Walch G. Reverse total shoulder arthroplasty for primary glenohumeral osteoarthritis in patients with a biconcave glenoid. J Bone Joint Surg Am. 2013;95:12971304.

34. Neer CS 2nd, Morrison DS. Glenoid bone-grafting in total shoulder arthroplasty. J Bone Joint Surg Am. 1988;70:1154-1162.

35. Neto JO, Gesser RL, Steglich V, Bonilauri Ferreira AP, Gandhi M, Vissoci JR, Pietrobon R. Validation of the Simple Shoulder Test in a Portuguese-Brazilian population: is the latent variable structure and validation of the Simple Shoulder Test Stable across cultures. PLoS One. 2013;8:e62890.

36. Nyffeler RW, Jost B, Pfirrmann CW, Gerber C. Measurement of glenoid version: conventional radiographs versus computed tomography scans. J Shoulder Elbow Surg. 2003;12:493-496.

37. Parks DL, Casagrande DJ, Schrumpf MA, Harmsen SM, Norris TR, Kelly JD 2nd. Radiographic and clinical outcomes of total shoulder arthroplasty with an all-polyethylene pegged bone ingrowth glenoid component: prospective short- to medium-term follow-up. J Shoulder Elbow Surg. 2016;25:246-255.

38. Pfahler M, Jena F, Neyton L, Sirveaux F, Molé D. Hemiarthroplasty versus total shoulder prosthesis: results of cemented glenoid components. J Shoulder Elbow Surg. 2006;15:154-163.

39. Press CM, O'Connor DP, Elkousy HA, Gartsman GM, Edwards TB. Glenoid perforation does not affect the short-term outcomes of pegged all-polyethylene implants in total shoulder arthroplasty. J Shoulder Elbow Surg. 2014;23:1203-1207.

40. Rice RS, Sperling JW, Miletti J, Schleck C, Cofield RH. Augmented glenoid component for bone deficiency in shoulder arthroplasty. Clin Orthop Relat Res. 2008;466:579-583.
41. Romeo AA, Mazzocca A, Hang DW, Shott S, Bach BR Jr. Shoulder scoring scales for the evaluation of rotator cuff repair. Clin Orthop Relat Res. 2004;427:107-114.

42. Roy JS, Macdermid JC, Faber KJ, Drosdowech DS, Athwal GS. The Simple Shoulder Test is responsive in assessing change following shoulder arthroplasty. J Orthop Sports Phys Ther. 2010;40:413-421.

43. Sabesan V, Callanan M, Ho J, Iannotti JP. Clinical and radiographic outcomes of total shoulder arthroplasty with bone graft for osteoarthritis with severe glenoid bone loss. J Bone Joint Surg Am. 2013;95:1290-1296.

44. Sabesan V, Callanan M, Sharma V, Iannotti JP. Correction of acquired glenoid bone loss in osteoarthritis with a standard versus an augmented glenoid component. J Shoulder Elbow Surg. 2014;23:964-973.

45. Sabesan VJ, Callanan M, Youderian AR, Iannotti JP. 3D CT assessment of the relationship between humeral head alignment and glenoid retroversion in glenohumeral osteoarthritis. $J$ Bone Joint Surg Am. 2014;96:e64.

46. Sears BW, Johnston PS, Ramsey ML, Williams GR. Glenoid bone loss in primary total shoulder arthroplasty: evaluation and management. J Am Acad Orthop Surg. 2012;20:604-613.

47. Shapiro TA, McGarry MH, Gupta R, Lee YS, Lee TQ. Biomechanical effects of glenoid retroversion in total shoulder arthroplasty. J Shoulder Elbow Surg. 2007;16(3 suppl):S90-95.

48. Somerson JS, Sander P, Bohsali K, Tibbetts R, Rockwood CA Jr, Wirth MA. What factors are associated with clinically important improvement after shoulder hemiarthroplasty for cuff tear arthropathy? Clin Orthop Relat Res. 2016;474:2682-2688.

49. Stephens SP, Spencer EE, Wirth MA. Radiographic results of augmented all-polyethylene glenoids in the presence of posterior glenoid bone loss during total shoulder arthroplasty. J Shoulder Elbow Surg. 2016;26:798-803.

50. Suarez DR, Nerkens W, Valstar ER, Rozing PM, van Keulen F. Interface micromotions increase with less-conforming cementless glenoid components. J Shoulder Elbow Surg. 2012;21:474-482.

51. Tashjian RZ, Deloach J, Green A, Porucznik CA, Powell AP. Minimal clinically important differences in ASES and simple shoulder test scores after nonoperative treatment of rotator cuff disease. J Bone Joint Surg Am. 2010;92:296-303.

52. van Kampen DA, van Beers LW, Scholtes VA, Terwee CB, Willems WJ. Validation of the Dutch version of the Simple Shoulder Test. J Shoulder Elbow Surg. 2012;21:808-814.

53. Walch G, Ascani C, Boulahia A, Nove-Josserand L, Edwards TB. Static posterior subluxation of the humeral head: an unrecognized entity responsible for glenohumeral osteoarthritis in the young adult. J Shoulder Elbow Surg. 2002;11:309-314.

54. Walch G, Badet R, Boulahia A, Khoury A. Morphologic study of the glenoid in primary glenohumeral osteoarthritis. J Arthroplasty. 1999;14:756-760.

55. Walch G, Boulahia A, Boileau P, Kempf JF. Primary glenohumeral osteoarthritis: clinical and radiographic classification. The Aequalis Group. Acta Orthop Belg. 1998;64(suppl 2):46-52.

56. Walch G, Mesiha M, Boileau P, Edwards TB, Levigne C, Moineau G, Young A. Three-dimensional assessment of the dimensions of the osteoarthritic glenoid. Bone Joint J. 2013;95:1377-1382

57. Walch G, Moraga C, Young A, Castellanos-Rosas J. Results of anatomic nonconstrained prosthesis in primary osteoarthritis with biconcave glenoid. J Shoulder Elbow Surg. 2012;21:1526-1533.

58. Walch G, Young AA, Boileau P, Loew M, Gazielly D, Mole D. Patterns of loosening of polyethylene keeled glenoid components after shoulder arthroplasty for primary osteoarthritis: results of a multicenter study with more than five years of follow-up. J Bone Joint Surg Am. 2012;94:145-150. 
59. Wang T, Abrams GD, Behn AW, Lindsey D, Giori N, Cheung EV. Posterior glenoid wear in total shoulder arthroplasty: eccentric anterior reaming is superior to posterior augment. Clin Orthop Relat Res. 2015;473:3928-3936.

60. Wijeratna M, Taylor DM, Lee S, Hoy G, Evans MC. Clinical and radiographic results of an all-polyethylene pegged bone-ingrowth glenoid component. J Bone Joint Surg Am. 2016;98:1090-1096.

61. Wirth MA, Loredo R, Garcia G, Rockwood CA Jr, Southworth C, Iannotti JP. Total shoulder arthroplasty with an all-polyethylene pegged bone-ingrowth glenoid component: a clinical and radiographic outcome study. J Bone Joint Surg Am. 2012;94:260-267.

62. Wylie JD, Beckmann JT, Granger E, Tashjian RZ. Functional outcomes assessment in shoulder surgery. World J Orthop. 2014;5:623-633.
63. Yian EH, Werner CM, Nyffeler RW, Pfirrmann CW, Ramappa A, Sukthankar A, Gerber C. Radiographic and computed tomography analysis of cemented pegged polyethylene glenoid components in total shoulder replacement. J Bone Joint Surg Am. 2005;87:1928-1936.

64. Youderian AR, Napolitano LA Jr, Davidson IU, Iannotti JP. Management of glenoid bone loss with the use of a new augmented all-polyethylene glenoid component. Tech Shoulder Elbow Surg. 2012;13:163-169.

65. Young AA, Walch G, Boileau P, Favard L, Gohlke F, Loew M, Mole D. A multicentre study of the long-term results of using a flat-back polyethylene glenoid component in shoulder replacement for primary osteoarthritis. $J$ Bone Joint Surg Br. 2011;93:210-216. 